\title{
Electron microscope appearances of juvenile and Peutz-Jeghers polyps
}

\author{
R. O. WELLER AND I. MCCOLL \\ From the Departments of Pathology and Surgery, Guy's Hospital, London
}

EDITORIAL SYNOPSIS Electron microscopy supports the view that these polyps are hamartomatous and not neoplastic.

The expression 'polyposis coli' is synonymous with 'multiple adenomatosis' of the large intestine and is well recognized as a precancerous condition. Juvenile polyposis coli, however, is a condition clinically and pathologically distinct from adenomatosis (McColl, Bussey, Veale, and Morson, 1964; Veale, McColl, Bussey, and Morson, 1965) and is not thought to have any malignant potential (Knox, Miller, Begg, and Zintel, 1960). Adenomatous polyps are due to neoplastic proliferation of intestinal epithelium. In contrast juvenile polyps are thought to be hamartomas of the connective tissue element (Morson, 1962). The polyps of the PeutzJeghers syndrome are found in both small and large intestine and are also hamartomas (Bartholomew, Moore, Dahlin, and Waugh, 1962) but the malformation is primarily an abnormality of the muscularis mucosae (Morson, 1962).

The purpose of this study was to determine whether the electron microscope appearances of juvenile and Peutz-Jeghers polyps showed any features which might confirm their hamartomatous nature.

\section{MATERIAL}

Colonic polyps from three patients with juvenile polyposis and one with the Peutz-Jeghers syndrome were examined with both light and electron microscopes. Two were obtained from the Hospital for Sick Children, Great Ormond Street, London. The first patient was a boy of 5 years, who had juvenile polyps throughout the colon and underwent a colectomy and ileorectal anastomosis. A large lipoma was removed from his back at the same time. The other boy, aged 4 , had a colectomy and ileorectal anastomosis for juvenile polyposis coli. He also had a Meckel's diverticulum and an arrested hydrocephalus. A 21-year-old patient at St. Mark's Hospital, London, had a ventricular septal defect and multiple juvenile polyps throughout the colon. The Peutz-Jeghers syndrome occurred in a 40-year-old patient from Guy's Hospital, who had a single colonic polyp and four jejunal polyps, which were not studied with the electron microscope. The histological diagnosis was made in all cases by examining paraffin sections with the light microscope.

Small pieces of each polyp and normal mucosa were immersed in cold $1 \%$ buffered osmium tetroxide for four hours (Palade, 1952), dehydrated in alcohol, stained with $1 \%$ phosphotungstic acid, and embedded in araldite. Sections $3 \mu$ thick were examined with the light microscope and suitable areas of the block containing epithelial cells and lamina propria were selected for examination with the electron microscope.

\section{RESULTS}

No generalized abnormal elements indicative of neoplasia were found in the polyps examined. The mucosa of the polyps consisted of columnar absorptive cells and mucus-secreting cells (Fig. 1) as in normal colon. The columnar cells were in close apposition throughout most of their length, with terminal bars (zonula occludens) at the luminal end, and with zonulae adhaerentes (Farquhar and Palade, 1963) at various points along the rest of the adjacent cell surfaces. The basal portions of the cells, however, were not in close contact and there were lacunae between them. There were projections from the cell surface which interdigitated and some formed desmosomes not only with other absorptive cells but also with mucous cells (Fig. 2). Microvilli, about $1 \mu$ in length and $0.5 \mu$ in width, projected from the luminal surface of the absorptive cells (Fig. 1). The mucous cells were fully mature and many seemed to be on the point of discharging mucus into the lumen. The nuclei, mitochondria, and other organelles appeared normal in all the epithelial cells and no abnormal cellular inclusions were observed. The bases of the cells were associated with a basement membrane which in all cases was intact (Figs. 2 and 3).

On the other side of the basement membrane there were fibroblasts and a layer of fine collagen 


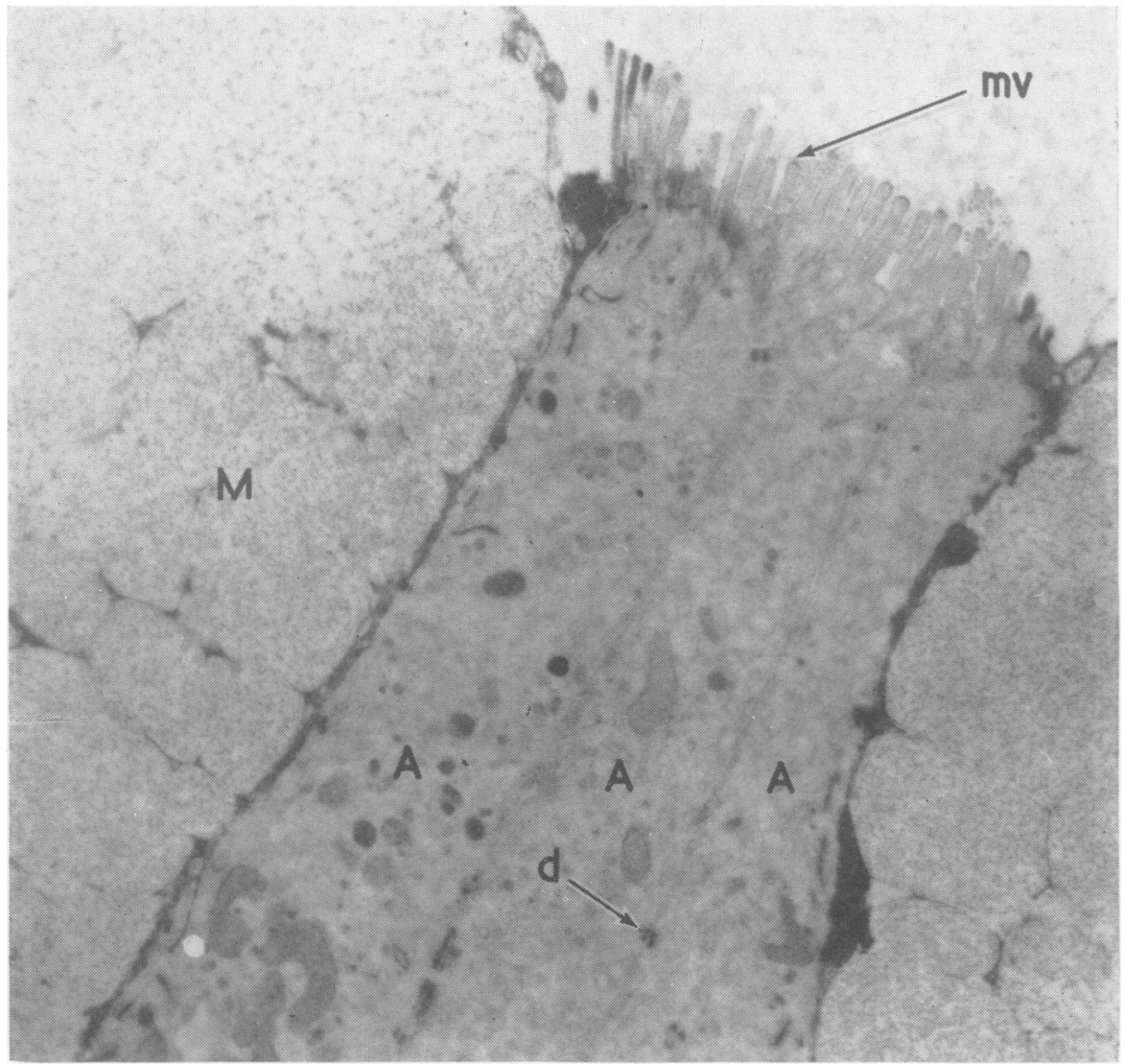

FIG. 1. Electron micrograph of mucosal cells from a Peutz-Jeghers polyp. Absorptive cells $(A)$ have microvilli $(m v)$ on the luminal border and there are zonulae adhaerentes $(d)$ along the opposing cell surfaces. Mucous cell $(M) \times 12,000$.

fibres $500 \AA$ in diameter. Also found in this region of the lamina propria were polymorphonuclear leucocytes, lymphocytes, plasma cells, mast cells, macrophages, capillaries, lymphatics, and nerve fibres. The latter were unmyelinated axons (Figs. 4 and 5) which were similar in appearance and size range, $0 \cdot 4 \mu-1 \mu$ in diameter, to the tertiary fibres described in the small intestine in the rat (Richardson, 1960). Around the Schwann cell was a characteristic sheath of fine endoneurial collagen. The cellular content of the lamina propria of normal colon differed from that of the polyps in only two respects: in the normal colon cells were more closely packed together and more collagen was present but there was no difference in the diameter of the collagen fibres.

\section{DISCUSSION}

No abnormal elements were demonstrated in these juvenile and Peutz-Jeghers polyps. No sign of neoplasm was noted. The appearances of the cells were virtually the same as those of normal colon. This is further support for the view that these lesions are hamartomas and not neoplasms.

The significance of nerve fibres in the lamina propria of juvenile polyps is difficult to evaluate. It is doubtful whether they occur in the stroma of neoplastic lesions (Tuqan, 1964) but no conclusion can be drawn without further electron microscope studies of neoplastic tissue. It is worth emphasizing that all the elements seen in these polyps with the help of the electron microscope appeared normal.

We are much indebted to Professor Hedley Atkins, Dr. Basil Morson, Sir C. Naunton Morgan, and Mr. H. H. Nixon for their help and permission to study their patients and to the National Spastics Society for the use of the electron microscope. 


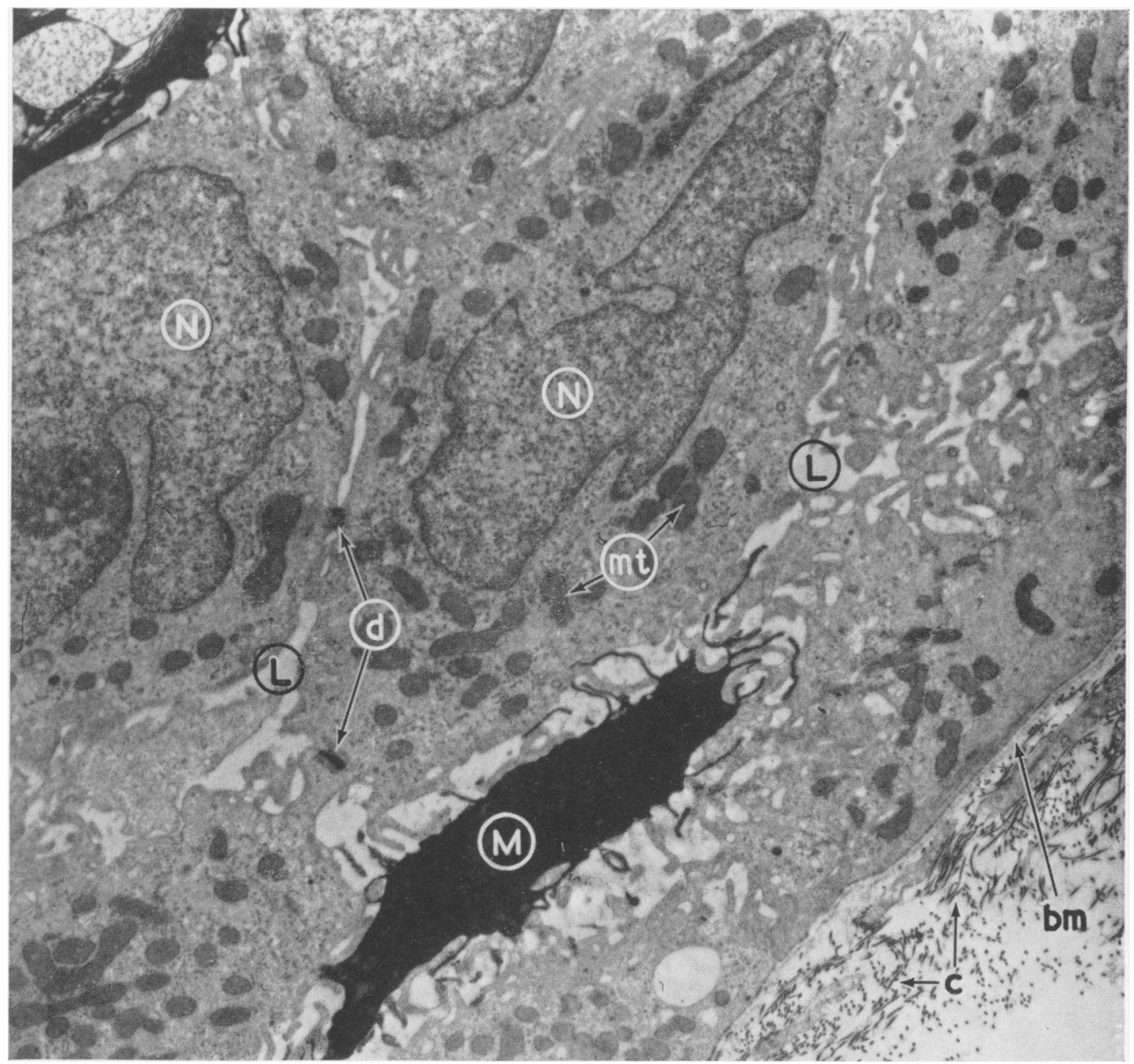

FIG. 2. Transverse section of the basal portions of mucosal cells from a Peutz-Jeghers polyp showing cellular processes interdigitating with those of neighbouring cells. Lacunae $(L)$, desmosome (macula adhaerens) $(d)$, nucleus $(N)$, mitochondria $(\mathrm{mt})$, basement membrane $(\mathrm{bm})$, basal portion of a mucous cell $(M)$, collagen $(\mathrm{c}) . \times 12,000$. 


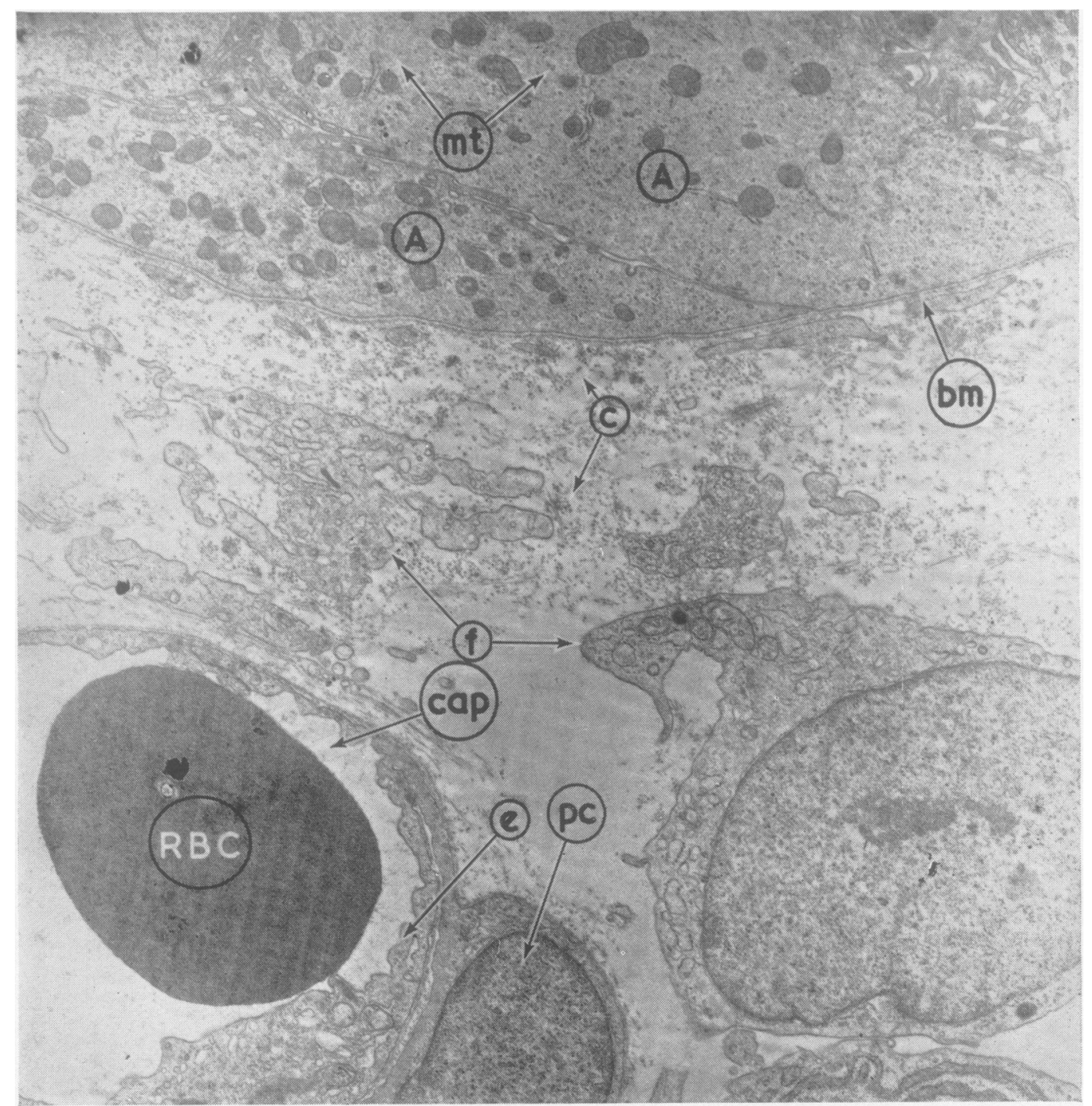

FIG. 3. Part of the lamina propria of a juvenile polyp. The basement membrane $(\mathrm{bm})$ is closely opposed to the mucosal cells $(A)$; collagen $(c)$, fibroblasts $(f)$. The capillary (cap) has a pericyte $(p c)$ and a lining of endothelial cells $(e)$. Red blood cell $(R B C) . \times 9,200$. 


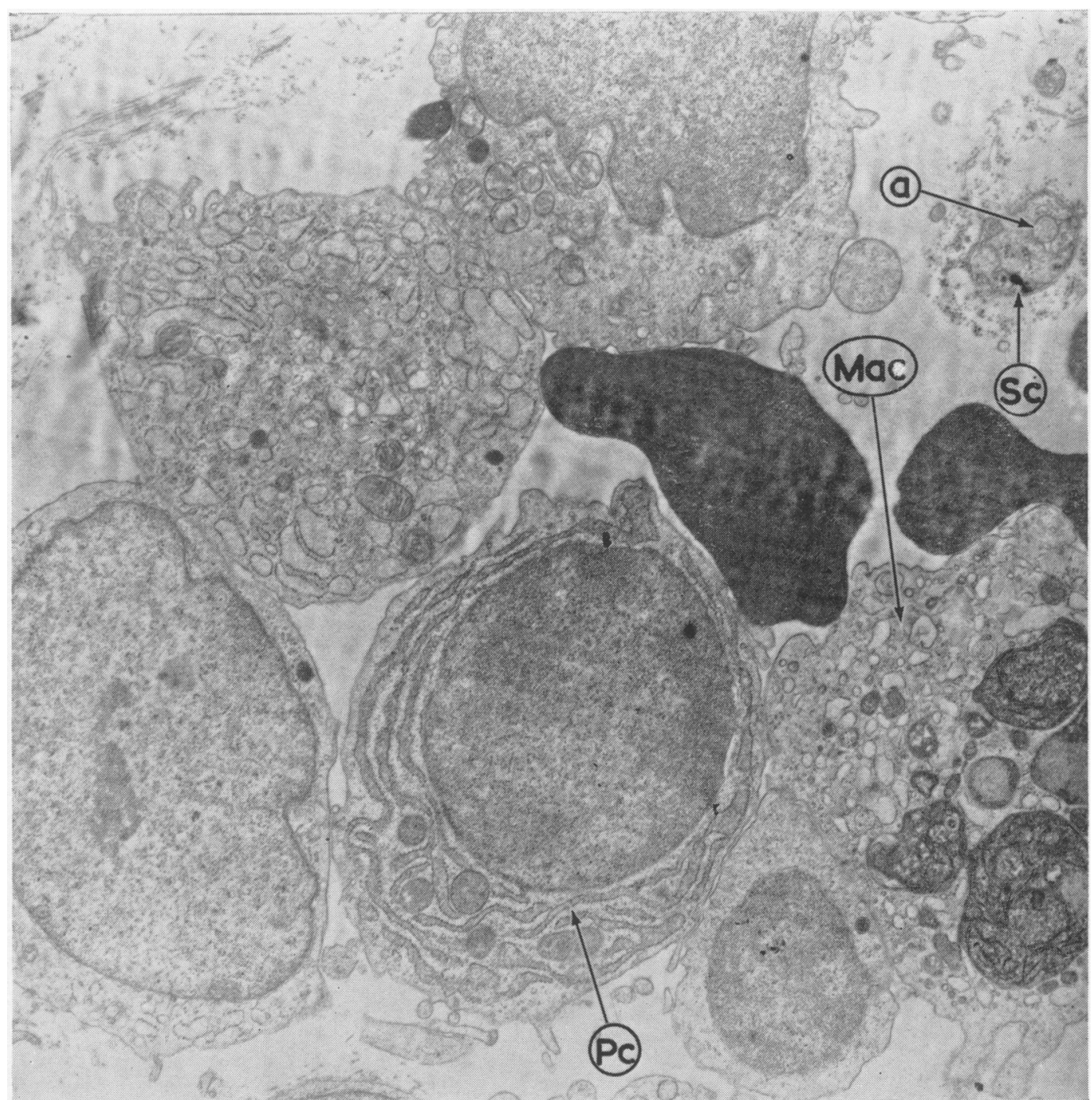

FIG. 4. Lamina propria of a juvenile polyp. Among the plasma cells $(P c)$ and macrophages (Mac) there is a Schwann cell (sc) which contains unmyelinated nerves $(a)$ and is surrounded by a sheath of fine collagen. $\times 9,200$.

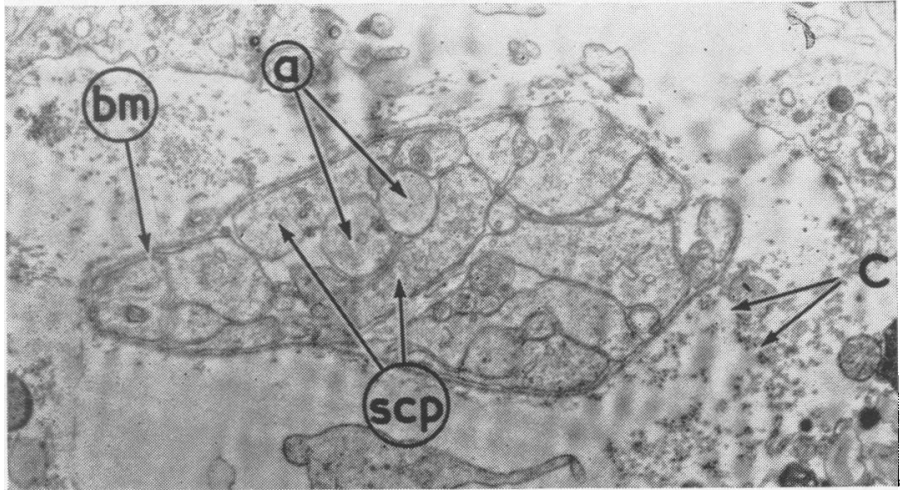

FIG. 5. Schwann cell containing unmyelinated axons in the lamina propria of a juvenile polyp. There are many Schwann cell processes (scp) surrounding the axons (a). There is an investing basement membrane (bm) and a sheath of collagen $(c) . \times 9,200$. 


\section{REFERENCES}

Bartholomew, L. G., Moore, C. E., Dahlin, D. C., and Waugh, J. M. (1962). Intestinal polyposis associated with mucocutaneous pigmentation. Surg. Gynec. Obstet., 114, 1-11.

Farquhar, M. G., and Palade, G. E. (1963). Junctional complexes in various epithelia. J. Cell. Biol., 17, 375-412.

Knox, W. G., Miller, R. E., Begg, C. F., and Zintel, H. A. (1960). Juvenile polyps of the colon. Surgery, 48, 201-210.

McColl, I., Bussey, H. J. R., Veale, A. M. O., and Morson, B. C. (1964). Juvenile polyposis coli. Proc. roy. Soc. Med., 57, 896-897.
Morson, B. C. (1962). Some peculiarities in the histology of intestinal polyps. Dis. Colon Rect., 5, 337-344.

Palade, G. E. (1952). A study of fixation for electron microscopy. J. exp. Med., 95, 285-297.

Richardson, K. C. (1960). Studies on the structure of autonomic nerves in the small intestine, correlating the silver-impregnated image in light microscopy with the permanganate-fixed ultrastructure in electronmicroscopy. J. Anat. (Lond.), 94, 457-472.

Tuqan, N. A. (1964). The stroma, its descriptive and applied anatomy. Guy's Hosp. Rep., 113, 111-121.

Veale, A. M. O., McColl, I., Bussey, H. J. R., and Morson, B. C. (1966). Juvenile polyposis coli. J. med. Genet., 3, 5-16.

\section{}

